\title{
EDITORIAL
}

\section{The role of nerve growth factor in Alzheimer's disease ${ }^{1}$}

Neuronal development and outgrowth are now known to be dependent on the releas: of neurotrophic factors (Easter et al. 1985). The most well characterized of these is Nerve Growth Factor (NGF). First identified by Rita Levi-Montalcini in the 1950s, it is essential for the development and maintenance of the sensory and sympathetic ganglia in the peripheral nervous system (for review see Levi-Montalcini \& Angeletti, 1968). NGF is a complex protein consisting of three subunits: alpha, beta and gamma. The beta subunit has been sequenced (Ullrich et al. 1983) and is responsible for the biological activity (Greene et al. 1971).

In the peripheral nervous system NGF is synthesized by the target tissue. NGF mRNA is present in these tissues and correlates well with the density of sympathetic innervation (Shelton \& Reichardt, 1984). This secreted NGF acts on local neuronal membrane receptors, it is internalized and transported retrogradely to the cell body where it mediates its trophic actions. These include maintenance of cell function, inducing neuritic extension and synthesis of the catecholamine synthesizing enzymes. Having established its physiological importance peripherally evidence is now accumulating for a role in the central nervous system (CNS).

In the CNS NGF selectively maintains the cholinergic system whereas the monoamine pathways are independent of its effects (Schwab et al. 1979). NGF levels in the rat brain are highest in the hippocampus, cortex and basal forebrain, particularly in the area of origin of the ascending cholinergic neurons of the forebrain bundle. In addition, Gnahn et al. (1983) found that exogenous NGF injected into the target areas of the cholinergic forebrain bundle in rats is retrogradely transported to the cholinergic cell bodies in the basal area and this is accompanied by a rise in choline acetyltransferase.

In the human brain, there are high levels of NGF mRNA in the hippocampus and cortex (Goedert et al. 1986), which are target areas for the ascending cholinergic basal forebrain bundle. NGF-receptors are expressed on the cholinergic neurons of the basal forebrain and can be demonstrated on their dendrites in the target areas (Allen et al. 1989). This suggests that NGF is produced by these target areas so as to be retrogradely transported to the cholinergic cell bodies in the basal forebrain area.

Burgeoning research into the mechanisms of synaptic plasticity combined with an improved understanding of the cellular mechanisms underlying several of the neurodegenerative disorders (Fine \& Rubin, 1988) raises the potential for a novel pharmacological reversal of neuronal degeneration, with accompanying restitution of function. In this respect the first attempts have focused on this being a possible therapeutic manoeuvre in Alzheimer's disease.

\section{ALZHEIMER'S DISEASE}

In Alzheimer's disease there is degeneration of specific acetylcholine neuronal pathways (Coyle et al. 1983) and neuronal loss in the locus ceruleus with decreased levels of noradrenaline in the cortex. However, there is no correlation between noradrenaline loss and clinical dementia (Perry et al. 1981). Numerous other neurotransmitters are implicated but the changes are poorly documented and the extent of their contribution to the cognitive deficits are unknown (Hefti \& Weiner, 1986).

The most consistent and well documented changes involve the ascending cholinergic pathways of the basal forebrain bundle. The cell bodies of these neurons, located in the septal area and the nucleus basalis of Meynert, innervate the amygdala, hippocampus, and neocortex. In Alzheimer's

' Address for correspondence: Dr I. P. Everall, The Maudsley Hospital, Denmark Hill, London SE5 8AZ. 
disease there is degeneration of these neurons which persist in a shrunken form and the levels of choline acetyl-transferase and acetylcholinesterase are decreased (Pearson et al. 1983). Diminution of these enzyme levels correlates with both the number of plaques and the clinical severity of dementia (Perry et al. 1978).

Application of this cholinergic hypothesis prompted clinical trials based on a simple deficit model of acetylcholine with attempted alleviation by administering the metabolic precursors. However, no clinically significant improvement has been recorded (Davis, 1985), reinforcing an argument that therapeutic interventions targeted at deficits in principal neurotransmitter systems are too simplistic and unlikely to yield useful results as the transmitter deficits are probably an epiphenomenon of the primary abnormality. The central cholinergic neurons are both dependent on NGF and atrophied in Alzheimer's disease. So theoretically a primary abnormality involving NGF would be expected to result in cholinergic cell degeneration and Alzheimer's disease.

\section{NERVE GROWTH FACTOR AND ALZHEIMER'S DISEASE}

The involvement of NGF in the ageing effects of the brain have been studied in rats. Goedert et al. (1986) initially reported no difference in the level of NGF mRNA in young or aged rat brains. However, this conflicted with Larkfors et al. (1987) who, using rats known for age dependent changes, noted significant falls in the levels of both NGF and NGF mRNA in aged rats. Cognitive impairments in aged rats, as assessed by maze test performance, are due to degenerative changes in the forebrain cholinergic neurons (Fischer et al. 1989). These cognitive impairments are reversed with cerebral intraventricular infusion of NGF (Fischer et al. 1987). Similarly, in aged rats NGF receptors, based on immunoreactivity, are limited to the cell body and absent in the dendrites, whereas in young adult rats they are distributed all over the dendritic tree (Gomez-Pinilla et al. 1989).

A similar distribution of NGF receptor immunoreactivity has been found in the forebrain cholinergic neurons and their fibres in human brains (Allen et al. 1989) with the Alzheimer's disease brains showing receptor immunoreactivity restricted to the cell bodies (Goedert et al. 1989). This indicates an abnormality in the synthesis or expression of NGF receptors as the level of NGF mRNA is unaffected in Alzheimer's disease, indicating that the production of this factor is undisturbed.

\section{COMMENT: IMPLICATIONS FOR TREATMENT}

The possibility of restitution of neuronal function using orally absorbed active fragments of NGF is an exciting prospect in the possible treatment of Alzheimer's disease. Such an approach is less naive than cholinergic replacement strategies, and less invasive than recent suggestions of neural tissue transplantation. However, the situation is not as simple as it at first appeared. Recent post mortem studies suggest that there is already a vigorous stimulation of NGF activity in the basal forebrain in Alzheimer's disease as judged by somatodendritic sprouting (Uchida \& Tomonga, 1989). This study claims that the underlying deficit in Alzheimer's disease may also involve a loss of inhibitory neurotrophic factors, suggesting an imbalance of delicate homeostatic mechanisms responsible for the maintenance of cell integrity. Furthermore, since ageing alone is accompanied by a loss of NGF receptors (Gomez-Pinilla et al. 1989) independently of the pathological process, the substrate for NGF therapy may not be present in elderly demented patients.

\section{CONCLUSION}

Clearly there is realistic potential for the treatment of Alzheimer's disease and other neurodegenerative disorders via manipulation of these mechanisms. The development simply of an NGF analogue does not take into account the complexity of the system and may be just as naive as previous attempts at treating the disease with choline. In order to avoid yet another 
disappointment in the drug treatment of dementia, the therapeutic enthusiasm for this approach is best held in abeyance until more basic biochemical details are elucidated.

I. P. EVERALL AND R. KERWIN

\section{REFERENCES}

Allen, J. S., Dawbarn, D., Wilcock, G. K., Moss, T. H. \& Semenenko, F. M. (1989). The distribution of beta-growth factor receptorimmunoreactive neurones in the human basal forebrain. Journal of Comparative Neurology (in the press).

Coyle, J. T., Price, D. L. \& DeLong, M. R. (1983). Alzheimer's disease: a disorder of cortical cholinergic innervation. Science 219 , $1184-1190$.

Davis, P. (1985). Is it possible to design rational treatment for the symptoms of Alzheimer's disease? Drug Development and Research $5,69-75$.

Easter, S. S., Purves, D., Rakic, P. \& Spitzer, N. C. (1985). The changing view of neuronal specificity. Science 230, 507-511.

Fine, R. E. \& Rubin, J. B. (1988). Specific trophic factor receptor interactions. Key selective elements in brain development and 'regeneration'. Journal of the American Geriatric Society 36, $457-466$.

Fischer, W., Wictorin, K., Bjorklund, A., Williams, L. R., Varon, S. \& Gage, F. H. (1987). Amelioration of cholinergic neuron atrophy and spatial memory impairment in aged rats by nerve growth factor. Nature 329, 65-68.

Fischer, W., Gage, F. H. \& Bjorklund, A. (1989). Degenerative changes in the forebrain cholinergic nuclei correlate with cognitive impairments in aged rats. European Journal of Neuroscience 1, 3445.

Gnahn, H., Hefti, F., Heumann, M.E., Schwab, H. \& Thoenen, D. (1983). NGF-mediated increase of choline acetyltransferase (ChAT) in the neonatal rat forebrain: evidence for a physiological role of NGF in the brain? Developmental Brain Research 9, 45-52.

Goedert, M., Fine, A., Hunt, S. P. \& Ullrich, A. (1986). Nerve growth factor mRNA in peripheral and central rat tissues and the human central nervous system: lesion effects in the rat brain and levels in Alzheimer's disease. Molecular Brain Research 1, 85-92.

Goedert, M., Fine, A., Dawbarn, D., Wilcock, G. K. \& Chao, M.V. (1989). Nerve growth factor receptor mRNA distribution in human brain: normal levels in basal forebrain in Alzheimer's disease. Molecular Brain Research 5, 1-7.

Gomez-Pinilla, F., Cotman, C. W. \& Nieto-Sampedro, M. (1989). NGF receptor immunoreactivity in aged rat brain. Brain Research 479, 255-262.

Greene, L. A. S., Varon, A., Piltch, A. \& Shooter, E. M. (1971).
Substructure of the beta-subunit of mouse $7 \mathrm{~s}$ nerve growth factor. Neurobiology 1, 37-48.

Hefti, F. \& Weiner, W. J. (1986). Nerve growth factor and Alzheimer's disease. Annals of Neurology 20, 275-281.

Larkfors, L., Ebendal, T., Whittemore, S. R., Persson, H., Hoffer, B. \& Olson, L. (1987). Decreased levels of nerve growth factor (NGF) and its messenger RNA in the aged rat brain. Molecular Brain Research 3, 55-60.

Levi-Montalcini, R. \& Angeletti, P. U. (1968). Nerve Growth Factor. Physiology Review 48, 534-569.

Pearson, R. C. A., Sofroniew, M. V., Cuello, A. C., Powell, T. P. S. Eckenstein, F., Esiri, M. M. \& Wilcock, G. K. (1983). Persistence of cholinergic neurons in the basal nucleus in a brain with senile dementia of the Alzheimer's type demonstrated by immunohistochemical staining for choline acetyltransferase. Brain Research 289, 375-379.

Perry, E. K., Tomlinson, B. E., Blessed, G., Bergmann, K., Gibson, P. H. \& Perry, R. H. (1978). Correlation of cholinergic abnormalities with senile plaques and mental test scores in senile dementia. British Medical Journal ii, 1457-1459.

Perry, E. K., Tomlinson, B. E., Blessed, G., Perry, R., Cross, A. J. \& Crow, T. J. (1981). Neuropathological and biochemical observations on the noradrenergic system in Alzheimer's disease. Journal of Neurological Science 51, 279-287.

Schwab, M. E., Otten, U., Agid, Y. \& Thoenen, H. (1979). Nerve growth factor (NGF) in the rat CNS: absence of specific retrograde axonal transport and tyrosine hydroxylase induction in locus coerulus and substantia nigra. Brain Research 168, 473-483.

Shelton, D. L. \& Reichardt, L. F. (1984). Expression of the beta nerve growth factor gene correlates with the density of sympathetic innervation in effector organs. Proceedings of the National Academy of Science. USA 81, 7951-7955.

Uchida, Y. \& Tomonaga, M. (1989). Neurotrophic action of Alzheimer's disease brain extract is due to loss of inhibitory factors for survival and neurite formation of cerebral cortical neurons. Brain Research 481, 190-193.

Ullich, A., Gray, A., Bergman, C \& Dull, T. J. (1983). Human betanerve growth factor gene sequence highly homologous to that of mouse. Nature 303, 821-825. 